\title{
Intermolecular interaction analysis from SCXRD and their relationship with observed properties in potential pharmaceuticals
}

\author{
N. Alvarez ${ }^{1}$, A. J. Costa-Filho ${ }^{2}$, J. Ellena ${ }^{3}$, G. Facchin ${ }^{1}$ \\ ${ }^{1}$ Facultad de Química, Universidad de la República, Montevideo, Uruguay, ${ }^{2}$ Faculdade de Filosofia, Ciências e Letras de Ribeirão \\ Preto, Universidade de São Paulo, SP, Brazil, ${ }^{3}$ Instituto de Física de São Carlos, Universidade de São Paulo, SP, Brazil, \\ alvarez@fq.edu.uy
}

There are already several examples of successful potential antineoplasic copper complexes which have completed pre-clinical trials, such as Casiopeína-III-ia [1] with copper(II) and HydroCuP® [2] with copper(I), that show high selectivity towards cancer cells. This work presents some of the structure-property relationships that we have determined in different potential antitumor agents during the last years in the laboratory. We focused particularly in intermolecular interactions in the crystal structure and their relationship with the lipophilicity of the compounds and the extent and mode of interaction with DNA, considered one of the main target biomolecule for complexes with planar aromatic ligands.

In the study of copper(I) ternary complexes with diimine and triphenylphosphine ligands there is a relationship between the percentage of polar interactions seen in the 2D fingerprint plot derived from Hirshfeld surface analysis and the experimentally determined lipophilicity [3]. Heteroleptic copper(II)-neocuproine complexes were also studied using L-dipeptides as co-ligands to regulate the lipophilicity of the obtained complexes and their ability to interact with DNA (Fig. 1). Studies confirmed that the complex with the most C-C interactions is the only one that interacts with DNA through partial intercalation, whereas the rest interact through groovebinding [4]. We are currently working in complex-model membrane interactions through an interdisciplinary approach that includes the use of full interaction maps to aid the understanding of the experimental and molecular modelling docking results.

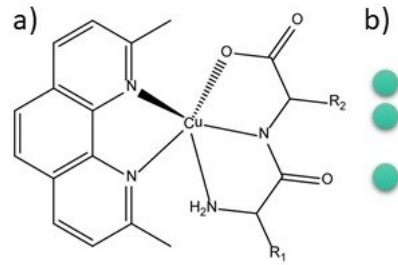

c)

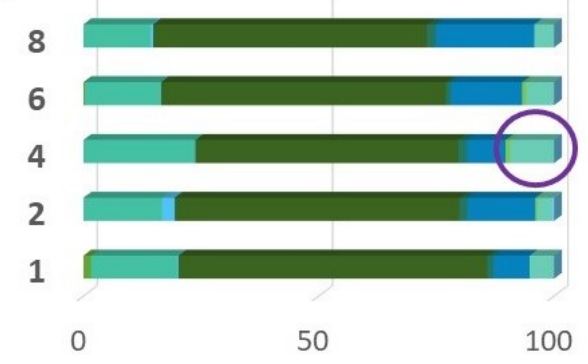

(1) L-Gly-Val $\mathrm{R}_{1}: \mathrm{H} \mathrm{R}_{2}: \mathrm{CHCH}_{3} \mathrm{CH}_{3}$ (5) L-Ala-Phe $\mathrm{R}_{1}: \mathrm{CH}_{3} \mathrm{R}_{2}: \mathrm{CH}_{2} \mathrm{C}_{6} \mathrm{H}_{6}$

(2) L-Gly-Leu $\mathrm{R}_{1}: \mathrm{H} \mathrm{R}_{2}: \mathrm{CH}_{2} \mathrm{CHCH}_{3} \mathrm{CH}_{3} \mathrm{O}$ (6) L-Val-Phe $\mathrm{R}_{1}: \mathrm{CHCH}_{3} \mathrm{CH}_{3} \mathrm{R}_{2}: \mathrm{CH}_{2} \mathrm{C}_{6} \mathrm{H}_{6}$

(3) L-Gly-Phe $\mathrm{R}_{1}: \mathrm{H} \mathrm{R}_{2}: \mathrm{CH}_{2} \mathrm{C}_{6} \mathrm{H}_{6} \quad$ (7) L-Phe-Ala $\mathrm{R}_{1}: \mathrm{CH}_{2} \mathrm{C}_{6} \mathrm{H}_{6} \mathrm{R}_{2}: \mathrm{CH}_{3}$

(4) L-Ala-Gly $\mathrm{R}_{1}: \mathrm{CH}_{3} \mathrm{R}_{2}: \mathrm{H}$ (8) L-Phe-Phe $\mathrm{R}_{1}: \mathrm{CH}_{2} \mathrm{C}_{6} \mathrm{H}_{6} \mathrm{R}_{2}: \mathrm{CH}_{2} \mathrm{C}_{6} \mathrm{H}_{6}$ d)

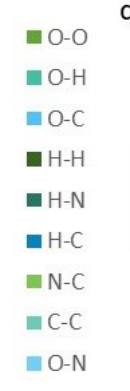

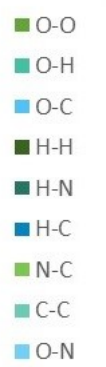

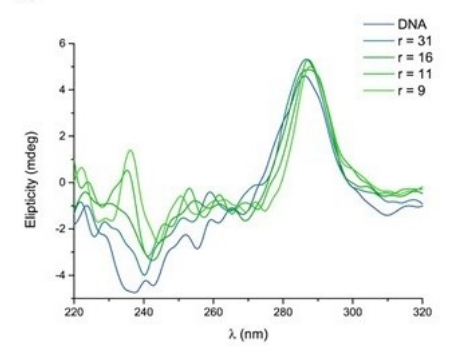

Figure 1. a) Proposed aqueous solution structure for [Cu(L-dipeptide)(neocuproine)] complex, b) list of L-dipeptides and corresponding complex, marked in green those with determined crystal structures, c) contact percentage distribution within the structure measured by Hirshfeld surface analysis, in purple the biggest $\mathrm{C}-\mathrm{C}$ contribution, d) circular dichroism studies of complex 4 confirming partial intercalation.

[1] Serment-Guerrero, J., et al. (2011). Toxicology In Vitro, 25(7), 1376-1384.

[2] Gandin, V., et al. (2017). Scientific Reports, 7(1), 13936.

[3] Alvarez, N., et al. (2014). Inorganica Chimica Acta, 466, 559-564.

[4] Alvarez, N., et al. (2020). Journal of Inorganic Biochemistry, 203, 110930.

\section{Keywords: Hirshfeld surface; DNA-interaction; lipophilicity; antitumor activity}

This work was supported by: FAPESP, CAPES (Brazil), CSIC and PEDECIBA (Uruguay). 